\title{
A percepção pública como instrumento de educação ambiental: Um estudo sobre
}

\section{microplásticos}

\author{
Public perception as an instrument of environmental education: A study on microplastics \\ La percepción pública como instrumento de educación ambiental: Un estudio sobre microplásticos
}

Recebido: 23/04/2021 | Revisado: 01/05/2021 | Aceito: 16/06/2021 | Publicado: 28/06/2021

\author{
Maria Lídia Oliveira Valim Coutinho Pereira \\ ORCID: https://orcid.org/0000-0001-8035-878X \\ Universidade Federal Fluminense, Brasil \\ E-mail: marialidia@id.uff.br \\ Lucianne Fragel-Madeira \\ ORCID: https://orcid.org/0000-0001-6747-2828 \\ Universidade Federal Fluminense, Brasil \\ E-mail:1fragel@id.uff.br \\ Rafael Ferreira dos Santos \\ ORCID: https://orcid.org/0000-0002-7164-6517 \\ Universidade Federal Fluminense, Brasil \\ E-mail: santosrafael@id.uff.br \\ Thaís Varandas de Azeredo Souza \\ ORCID: https://orcid.org/0000-0002-6388-6537 \\ Universidade Federal Fluminense, Brasil \\ E-mail: thaisvazeredo@gmail.com \\ Gustavo Henrique Varela Saturnino Alves \\ ORCID: https://orcid.org/0000-0002-9100-1986 \\ Universidade Federal Fluminense, Brasil \\ Instituto Federal de Educação, Ciência e Tecnologia do Rio de Janeiro, Brasil \\ E-mail: gh_alves@id.uff.br
}

\begin{abstract}
Resumo
O objetivo deste trabalho foi avaliar a percepção ambiental em relação aos microplásticos dos habitantes de diferentes cidades do estado do Rio de Janeiro. A pesquisa foi realizada durante as exposições do centro de ciências itinerante Ciências Sob Tendas na Semana Nacional de Ciência e Tecnologia de 2019, nas cidades de Niterói, Três Rios e Comendador Levy Gasparian,. Os dados foram coletados por meio de um formulário "Google Forms" com dez perguntas fechadas. No total foram coletadas 150 respostas em Niterói, 114 em Três Rios e 29 em Comendador Levy Gasparian. Quando perguntado se conheciam o termo "microplástico", em geral, 77\% das pessoas responderam "NÃO" e apenas 23\% já tinham ouvido falar deste termo. Entre as pessoas que conheciam o termo, $84 \%$ eram de Niterói, estavam no ensino médio ou superior e obtiveram informações pela internet ou ambiente escolar. Logo, observa-se que o fator mais determinante é a escolaridade, apesar disso, a maioria deste público não recicla seu lixo e nem sabe como os plásticos se decompõem na natureza. Como forma de apresentar e divulgar os microplásticos como agentes poluidores do ambiente, ao final do questionário, o visitante era convidado a participar da atividade "Descobrindo os Microplásticos". A atividade desenvolvida facilitou a conscientização e a transposição didática sobre os microplásticos de maneira contextualizada com a realidade dos participantes. Assim, a divulgação científica pode ser uma excelente ferramenta para estimular reflexões e mudança de hábitos, especialmente a respeito do lixo e seu descarte.
\end{abstract}

Palavras-chave: Lixo marinho; Divulgação científica; Percepção ambiental.

\begin{abstract}
The objective of this work was to evaluate the environmental perception in relation to microplastics of the inhabitants of different cities in the state of Rio de Janeiro. The research was carried out during the exhibitions of the traveling science center Sciences Under Tents at the National Week of Science and Technology of 2019, in the cities of Niterói, Três Rios and Comendador Levy Gasparian,. The data were collected using a "Google Forms" with ten closed questions. In total, 150 responses were collected in Niterói, 114 in Três Rios and 29 in Comendador Levy Gasparian. When asked if they knew the term "microplastic", in general, $77 \%$ of people answered "NO" and only $23 \%$ had heard of this term. Among the positive answers $84 \%$ of the people were from Niterói, were in high school or higher and obtained information through the internet or school environment. Therefore, it is observed that the most determining factor is education, despite this, the majority of this public does not recycle their garbage and does not even know how plastics decompose in nature. As a way of presenting and publicizing microplastics as polluting agents of the
\end{abstract}


environment, at the end of the questionnaire, the visitor was invited to participate in the activity "Discovering Microplastics". The developed activity facilitated the awareness and didactic transposition about microplastics in a contextualized way with the reality of the participants. Thus, scientific dissemination can be an excellent tool to stimulate reflections and change habits, especially regarding waste and its disposal.

Keywords: Marine waste; Scientific dissemination; Environmental perception.

\section{Resumen}

El objetivo de este trabajo fue evaluar la percepción ambiental en relación a los microplásticos de los habitantes de diferentes ciudades del estado de Río de Janeiro. La investigación se realizó durante las exposiciones del centro científico itinerante Sciences Under Tents en la Semana Nacional de Ciencia y Tecnología de 2019, en las ciudades de Niterói, Três Rios y Comendador Levy Gasparian. Los datos se recopilaron mediante un formulario de "Formularios de Google" con diez preguntas cerradas. En total, se recogieron 150 respuestas en Niterói, 114 en Três Rios y 29 en Comendador Levy Gasparian. Cuando se les preguntó si conocían el término "microplástico", en general, el 77\% de las personas respondió "NO" y solo el 23\% había oído hablar de este término. El 84\% de las personas que conocían los microplásticos eran de Niterói, estaban en la escuela secundaria o superior y obtuvieron información a través de Internet o del entorno escolar. Por tanto, se observa que el factor más determinante es la educación, a pesar de ello, la mayoría de este público no recicla su basura y ni siquiera sabe cómo se descomponen los plásticos en la naturaleza. Como forma de presentar y dar a conocer los microplásticos como agentes contaminantes del medio ambiente, al final del cuestionario se invitó al visitante a participar en la actividad "Descubriendo los microplásticos". La actividad desarrollada facilitó la sensibilización y transposición didáctica sobre los microplásticos de forma contextualizada con la realidad de los participantes. Así, la divulgación científica puede ser una excelente herramienta para estimular reflexiones y cambiar hábitos, especialmente en lo que respecta a los residuos y su disposición.

Palabras clave: Residuos marinos; Divulgación científica; Percepción ambiental.

\section{Introdução}

A invenção do plástico à base de um polímero sintético teve início em meados do Século XIX, considerado relativamente moderno quando comparado a outros materiais. O termo é derivado da palavra grega "Plastikos", que significa apto para moldagem. Isto se refere à maleabilidade do material durante a fabricação, o qual é capaz de ser fundido, moldado e transformado em uma variedade de formas (PlasticsEurope, 2018). Existem diferentes polímeros plásticos, os mais utilizados são o polipropileno (PP) e o polietileno (PE) que junto com o policloreto de vinila (PVC), poliestireno (PS) e polietileno tereftalato (PET) correspondem a 90\% da demanda de plástico (Andrady \& Neal, 2009).

Com a produção e uso em larga escala a partir da década de 1950, os plásticos continuaram a evoluir para os diversos propósitos e aplicações, se tornando um componente indispensável utilizado em todos os setores industriais (Galgani, Pham, \& Reisser, 2017). Entretanto, a produção atual cresceu rapidamente, de forma exponencial e sem controle, devido ao baixo custo, versatilidade e confiabilidade do material. Mundialmente já foram produzidas 8,3 bilhões de toneladas de plástico virgem e metade dessa quantidade foi feita partir de 2000 sendo que 75\% é resíduo (Geyer, Jambeck, \& Law, 2017; Kaza, Yao, BhadaTata, \& Van Woerden, 2018).

A princípio, as preocupações sobre a liberação de plástico no ambiente eram inexistentes. O material era visto como benigno, devido à sua inércia e percepção de falta de toxicidade (Worm, Lotze, Jubinville, Wilcox, \& Jambeck, 2017). Consequentemente (e devido à má gestão dos resíduos) um total estimado de 5 bilhões de toneladas de plástico foram descartados em aterros sanitários e no meio ambiente desde 1950 (Geyer et al., 2017).

Além disso, estima-se que um terço de todo o plástico descartado tenha se inserido na natureza como poluição terrestre, de água doce ou marinha e que $80 \%$ do plástico nos oceanos seja proveniente de fontes terrestres (de Souza Machado, Kloas, Zarfl, Hempel, \& Rillig, 2018; Jambeck et al., 2015; Kershaw, 2016). Nas últimas décadas, a poluição plástica tem recebido um maior destaque e atenção devido seu grande aumento nos ambientes aquáticos, correspondendo a cerca de $80 \%$ do lixo marinho (Derraik, 2002; Eriksen et al., 2014; Islam \& Tanaka, 2004; Moore, 2008) e por se tratar de um material de degradação lenta este se acumula no ambiente (Andrady, 2011). A exposição à radiação UV, as propriedades hidrolíticas da água, as propriedades oxidantes e a atividade microbiana contribuem para a degradação do plástico (Moore, 2008; Wilcox, 
Van Sebille, \& Hardesty, 2015; Worm et al., 2017).

Os detritos plásticos encontrados em sistemas aquáticos podem ser classificados de acordo com seu tamanho como nanoplásticos, microplásticos, mesoplásticos ou macroplásticos (da Costa, Santos, Duarte, \& Rocha-Santos, 2016). No entanto, não existe um consenso entre os autores sobre essa classificação e os limites de tamanho para cada categoria. Muitos trabalhos simplificam essa classificação e utilizam apenas a classificação de macroplásticos e microplásticos. Porém, estudos com nanoplásticos tem aumentado recentemente e demonstrado efeitos mais complexos (da Costa et al., 2016).

Os microplásticos são caracterizados como partículas plásticas entre $1 \mu \mathrm{m}$ e 5 mm (Andrady, 2011) e também podem ser classificados de acordo com sua origem em dois tipos: primários ou secundários (G P Olivatto, Carreira, Tornisielo, \& Montagner, 2018). Os microplásticos primários são plásticos produzidos em forma de pequenas partículas e utilizados em produtos como os de limpeza, higiene pessoal e cosméticos, e assim liberados diretamente no ambiente. Os microplásticos secundários são microplásticos provenientes da degradação de plásticos maiores em pequenos fragmentos de plástico expostos ao ambiente marinho. Isso acontece através de fotodegradação e outros processos de intemperismo de resíduos mal administrados, como sacos de plástico descartados ou de perdas não intencionais, tais como redes de pesca (Sharma \& Chatterjee, 2017; Sundt, Schulze, \& Syversen, 2014).

Os impactos negativos dos microplásticos são mais preocupantes do que os observados em partículas maiores. Além de gerarem efeitos agudos como obstrução do trato digestivo de organismos menores, são também responsáveis por causarem diversos efeitos crônicos, como por exemplo capacidade para alterar o funcionamento do sistema hormonal, que ainda não são totalmente compreendidos e podem provocar graves desequilíbrios ecológicos (Sul, 2014; Worm et al., 2017; Wright, Thompson, \& Galloway, 2013). Uma das preocupações com esses microplásticos dispersos na natureza, em especial no ambiente marinho, é sua bioacumulação. Uma vez que são incorporados por organismos dos níveis tróficos mais baixos da cadeia alimentar e, consequentemente, aumenta a disponibilidade para aqueles em níveis mais altos. Esse processo pode chegar ao ser humano considerando a expressividade da alimentação de origem marinha ao redor do mundo como peixes, moluscos, crustáceos entre outros (Sharma \& Chatterjee, 2017).

Além do risco que representa ao serem introduzidos na cadeia alimentar, os resíduos de plástico no ambiente marinho podem ser ainda mais perigosos. Esses fragmentos têm a capacidade de adsorver poluentes orgânicos como bifenilas policloradas (PCBs) e pesticidas organoclorados (OCPs), conhecidos como poluentes orgânicos persistentes (POPs) do ambiente e concentrá-los em até 1 milhão de vezes em relação às concentrações encontradas na água do mar (Mato et al., 2001). Embora haja evidências claras de transferência de uma variedade de poluentes adsorvidos pelos plásticos aos organismos, a capacidade de afetar diretamente a saúde humana e interações com tecidos ainda não foram plenamente elucidadas (Rochman, 2016; Sharma \& Chatterjee, 2017).

Os detritos de plástico são encontrados em todos os ambientes marinhos, dentre eles ambientes sensíveis de extrema importância como manguezais (Li, Zhang, Xue, \& Wang, 2019), recifes de corais (Hall, Berry, Rintoul, \& Hoogenboom, 2015), 2015), regiões insulares com elevado endemismo (Sul, 2014), sedimento de praias arenosas (Hengstmann, Tamminga, Vom Bruch, \& Fischer, 2018), de águas profundas (Van Cauwenberghe, Devriese, Galgani, Robbens, \& Janssen, 2015) e giros oceânicos subtropicais (Brach et al., 2018). Pesquisas recentes também documentaram na Antártica (Waller et al., 2017). No entanto, o sedimento da praia continua sendo o principal destino final do plástico depois de diversos impactos causados durante o seu ciclo de vida (Eriksen et al., 2014).

Além da degradação biológica, fotoquímica e por outros processos intempéricos, os plásticos afundam devido às propriedades do seu polímero, por organismos ou substâncias aderidas que alteram sua densidade e quantidade nos oceanos (Eriksen et al., 2014). Neste contexto, estudos sobre os microplásticos tem ganhado espaço no meio acadêmico. No Brasil, as pesquisas embora recentes (por exemplo Castro, da Silva, \& de Araújo, 2018; Sul, 2014), já demonstram que a poluição por 
plásticos e microplásticos no ambiente marinho e costeiro é onipresente, inclusive em praias da Baía de Guanabara (Dias, 2016; Glaucia P Olivatto, Martins, Montagner, Henry, \& Carreira, 2019).

Frente ao acelerado modelo de produção econômica, iniciado com a revolução industrial e cada vez mais acentuado (Amorim Filho, Kohler, \& Barroso, 2003), a superexploração descontrolada dos recursos naturais, bem como a cultura do consumo, torna-se indispensável a aplicação de estudos e programas de educação e percepção ambientais. Deste modo, na tentativa de se alcançar uma sustentabilidade capaz de suprir as necessidades da sociedade, parte-se do pressuposto de que através dos recursos naturais, a vida humana é sustentada, e assim cabem todas as possibilidades de explorá-los de maneira consciente (Cunha \& Leite, 2009).

Segundo a Política Nacional de Educação Ambiental (Brasil, 1999) "entendem-se por educação ambiental os processos por meio dos quais o indivíduo e a coletividade constroem valores sociais, conhecimentos, habilidades, atitudes e competências voltadas para a conservação do meio ambiente, bem de uso comum do povo, essencial à sadia qualidade de vida e sua sustentabilidade." Logo, a principal função da Educação Ambiental é a formação de cidadãos conscientes, preparados para a tomada de decisões e atuando na realidade socioambiental, com um comprometimento com a vida, o bem-estar de cada um e da sociedade, tanto a nível global como local (Melazo, 2005).

A percepção ambiental é o modo como cada indivíduo sente o ambiente ao seu redor, valorizando-o em maior ou menor escala. Atualmente, é um tema recorrente com grande potencial de contribuição para a tomada de consciência e prática de ações individuais e coletivas. Assim, o estudo sobre a percepção ambiental é importante para que se possa compreender melhor as interrelações entre o homem e o ambiente, suas expectativas, suas satisfações e insatisfações, julgamentos e condutas (Pacheco \& Silva, 2007).

Na educação ambiental, a percepção ambiental é capaz de auxiliar na criação de metodologias para despertar a tomada de consciência dos indivíduos frente aos problemas ambientais. Por meio da associação da percepção e educação ambientais é possível realizar trabalhos com bases locais, ou seja, saber como os indivíduos do objeto de pesquisa percebem o ambiente em que vivem, suas fontes de satisfações e insatisfações (Palma, 2005).

A educação ambiental pode ser desenvolvida em espaços formais e não formais de educação. O espaço formal de educação é o ambiente acadêmico com todas as suas dependências que está relacionado às Instituições Escolares da Educação Básica e do Ensino Superior, definidas na Lei 9394/96 de Diretrizes e Bases da Educação Nacional.

De acordo com Jacobucci (2008), os espaços não formais são constituídos por duas categorias: os espaços institucionais, que são regulamentados e que possuem equipe técnica responsável para desenvolver as atividades realizadas, tais como os museus, centros de ciências e de pesquisas, parques ecológicos, zoológicos, dentre outros. Além desses, há também a existência de espaços de educação não formais não institucionais, que são constituídos por parques, casas, ruas, praças, terrenos, cinemas, praias, cavernas, rios, lagoas e outros.

Deste modo, podemos afirmar que as atividades de educação ambiental podem ser realizadas em ambos os espaços apresentados por Jacobucci (2008). Isto porque, o avanço científico informacional criou novos espaços do conhecimento, que vão além do território escolar, que também podem ser considerados enquanto educativos, trazendo benefício aos sujeitos envolvidos e por consequência a melhoria da qualidade do meio ambiente. Assim, a divulgação científica presente nessas atividades exerce um posto fundamental, pois a mesma além de oferecer acessibilidade aos conhecimentos científicos, auxilia no processo de alfabetização científica (Bueno, 2010)

Desta forma o objetivo deste trabalho foi avaliar a percepção pública, em relação aos microplásticos, dos habitantes em diferentes cidades do estado do Rio de Janeiro, comparar a percepção ambiental da cidade litorânea (Niterói) e das interioranas (Três Rios e Comendador Levy Gasparian) e promover a conscientização ambiental a partir do desenvolvimento de uma atividade de educação ambiental sobre o uso e impactos dos microplásticos no meio ambiente. 


\section{Metodologia}

Essa pesquisa foi orienta por um viés descritivo e qualitativo como abordado por Soares et al (2018). Além disso, foi ambientada no Ciências Sob Tendas (CST), um centro de ciência itinerante, criado em 2013, que promove a popularização científica e estimula o interesse popular para os temas científicos a partir de exposições de baixo custo em espaços formais e não-formais de educação, como praças públicas e escolas (Alves et al., 2020). Visto o perfil itinerante e os ambientes visitados, o CST conta com cinco tendas, que constituem uma área total de cerca de $100 \mathrm{~m}^{2}$, e doze mesas desmontáveis, que possibilitam as exposições e montagem das atividades nas mais diversas realidades. Além do mais, todas as atividades do acervo são compactas e guardadas em caixas organizadoras de plástico de 60 litros (Alves, Marins, Pereira, \& Fragel-Madeira, 2019).

A pesquisa foi realizada durante as exposições do Ciências Sob Tendas na Semana Nacional de Ciência e Tecnologia nos dias 18, 19, 21 e 22 outubro de 2019, na cidade litorânea de Niterói, e nas cidades interioranas de Três Rios e Comendador Levy Gasparian, sendo os dois primeiros dias em Niterói e os outros nas cidades subsequentes. Os dados foram coletados por meio de um formulário "Google Forms" com dez perguntas fechadas (Chaer, Diniz, \& Ribeiro, 2012), através de um tablet. Uma pessoa da equipe era recrutada a fazer a pesquisa durante a exposição, a qual abordava os visitantes antes destes terem passado pela atividade. Primeiramente, obtinha-se o consentimento do visitante para realizar a pesquisa e depois o entrevistador explicava ao visitante que os dados seriam publicados em um estudo acerca do tema. Em seguida, realizava-se as perguntas descritas abaixo:

1. Qual a sua idade?

2. Qual é sua maior escolaridade concluída?

3. Já ouviu falar do termo "microplástico"?

Ao final desta seção, caso o indivíduo respondesse "não" o questionário era fechado, encerrando sua participação. E se respondesse "sim", prosseguia-se com mais sete perguntas.

4. Onde você ouviu falar?

5. Para você, quais destes produtos podem liberar microplásticos?

6. Você acha que o seu lixo gera microplásticos no ambiente?

7. Em sua residência, você e sua família separam o lixo comum do reciclado?

8. Como você acha que os plásticos se decompõem na natureza?

9. Você acha que os microplásticos podem afetar nossa saúde?

10. Quais destes seres vivos podem sofrer ou serem afetados pela poluição do meio ambiente com microplásticos?

No final da entrevista, todos os visitantes eram convidados a participarem da atividade Descobrindo os Microplásticos e a discutirem sobre as respostas que foram dadas ao questionário. As respostas foram armazenadas em uma planilha, os dados foram organizados e analisados pelo programa Microsoft Excel.

A atividade - Descobrindo os Microplásticos foi composta por amostras de microplásticos e uma pescaria para demonstrar a bioacumulação. As amostras de microplásticos foram extraídas com peneiras do sedimento arenoso e do mar das praias de Boa Viagem e Icaraí e, posteriormente, diluídas em água ou secas a temperatura ambiente. Além destas, também foram extraídas amostras de microplásticos de produtos de higiene, como sabonete e pasta de dente, a partir da dissolução, diluição em água e sucessivas filtrações com filtro de café. Por fim, para a visualização dos microplásticos durante a atividade foram utilizadas lupas de mão. Além disso, houve a demonstração de exemplos de produtos alternativos com menos contaminantes, tais como esfoliantes naturais e ecobags (Alves et al., 2020). 
Na pescaria foram utilizados dezesseis peixes de tecido feltro de diferentes tamanhos, com acesso às vísceras, feitas com fios de lã, contendo pedrinhas representando os microplásticos. Os peixes de tecido ficavam dentro de uma piscina inflável infantil com papel crepom azul cortado em tiras para a demonstração da água do mar e a pesca era praticada pelos visitantes com varas de pesca de 1,30m feitas de bambu com anzol de arame (Alves et al., 2020).

A dinâmica da atividade durante a exposição consistiu em um convite para uma brincadeira de pescaria, na qual os peixes pescados eram abertos e suas vísceras analisadas. A partir dessa análise eram apresentadas amostras reais de microplásticos e suas origens. Além disso, eram disponibilizadas lupas de mão para que o público pudesse observar mais atentamente o microplástico. Após a interação propunha-se uma discussão sobre os contaminantes presentes nos peixes, a bioacumulação pela cadeia trófica e formas de mitigar essa poluição.

\section{Resultados e Discussão}

No total foram coletadas 293 respostas ao questionário durante os quatro dias, sendo 150 respostas em Niterói e 143 respostas no interior, das quais 114 em Três Rios e 29 em Comendador Levy Gasparian. O público entrevistado foi majoritariamente jovem, o que corresponde ao público-alvo do projeto, com 143 pessoas de 8 a 16 anos de idade, 89 indivíduos de 17 a 29 anos, 54 participantes de 30 a 60 anos e 7 pessoas de 61 aos 90 anos de idade (Gráfico 1).

Gráfico 1 - O público entrevistado neste projeto consistiu majoritariamente de jovens. Gráfico da quantidade de pessoas entrevistadas por faixa etária. Os números acima do gráfico representam o valor absoluto de entrevistados. N=293.

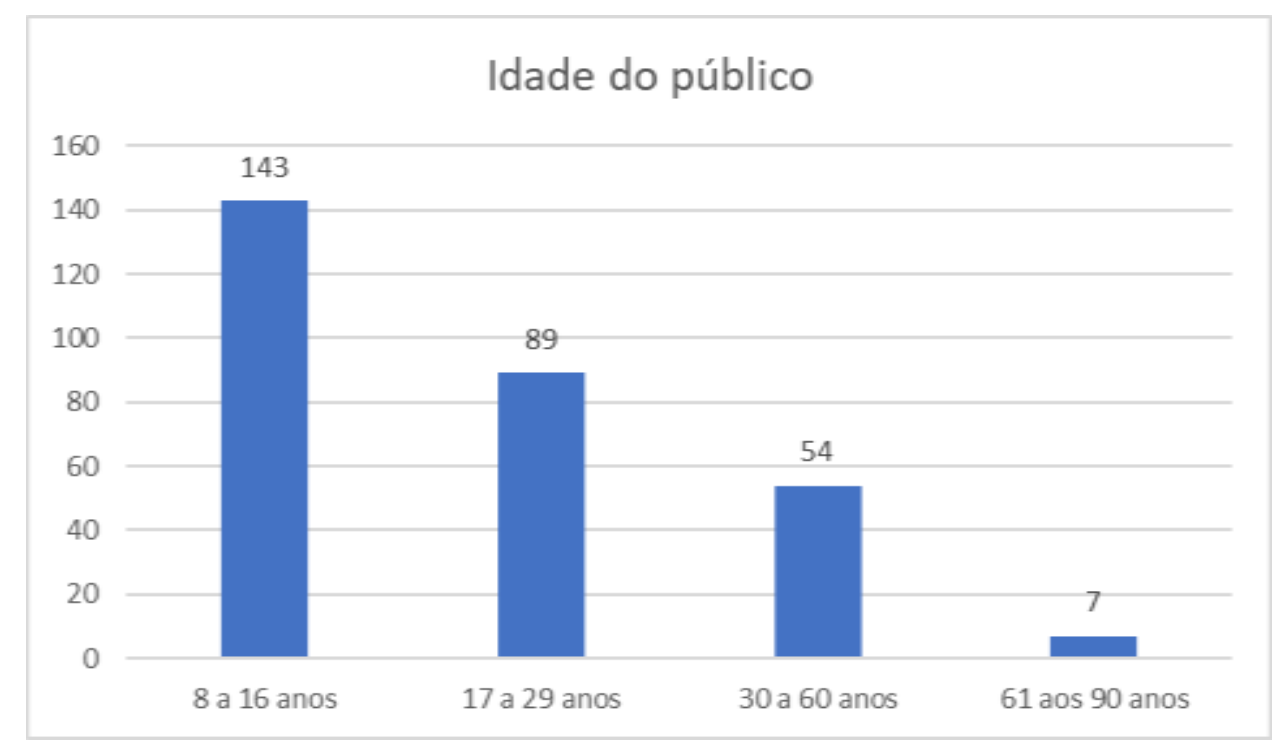

Fonte: Autores.

Em relação à escolaridade, a maior parte do público tinha o maior grau concluído no Ensino Médio, correspondente à 100 entrevistados, seguido pelo Ensino Fundamental II com 92 pessoas, Ensino Fundamental I com 49 indivíduos, Pósgraduação com 29 pessoas e Graduação com 23 entrevistados (Gráfico 2). 
Research, Society and Development, v. 10, n. 7, e45210715411, 2021

(CC BY 4.0) | ISSN 2525-3409 | DOI: http://dx.doi.org/10.33448/rsd-v10i7.15411

Gráfico 2 - Gráfico de quantidade de pessoas entrevistadas por escolaridade. Podemos observar que a maior parte eram alunos do ensino fundamental ou médio.

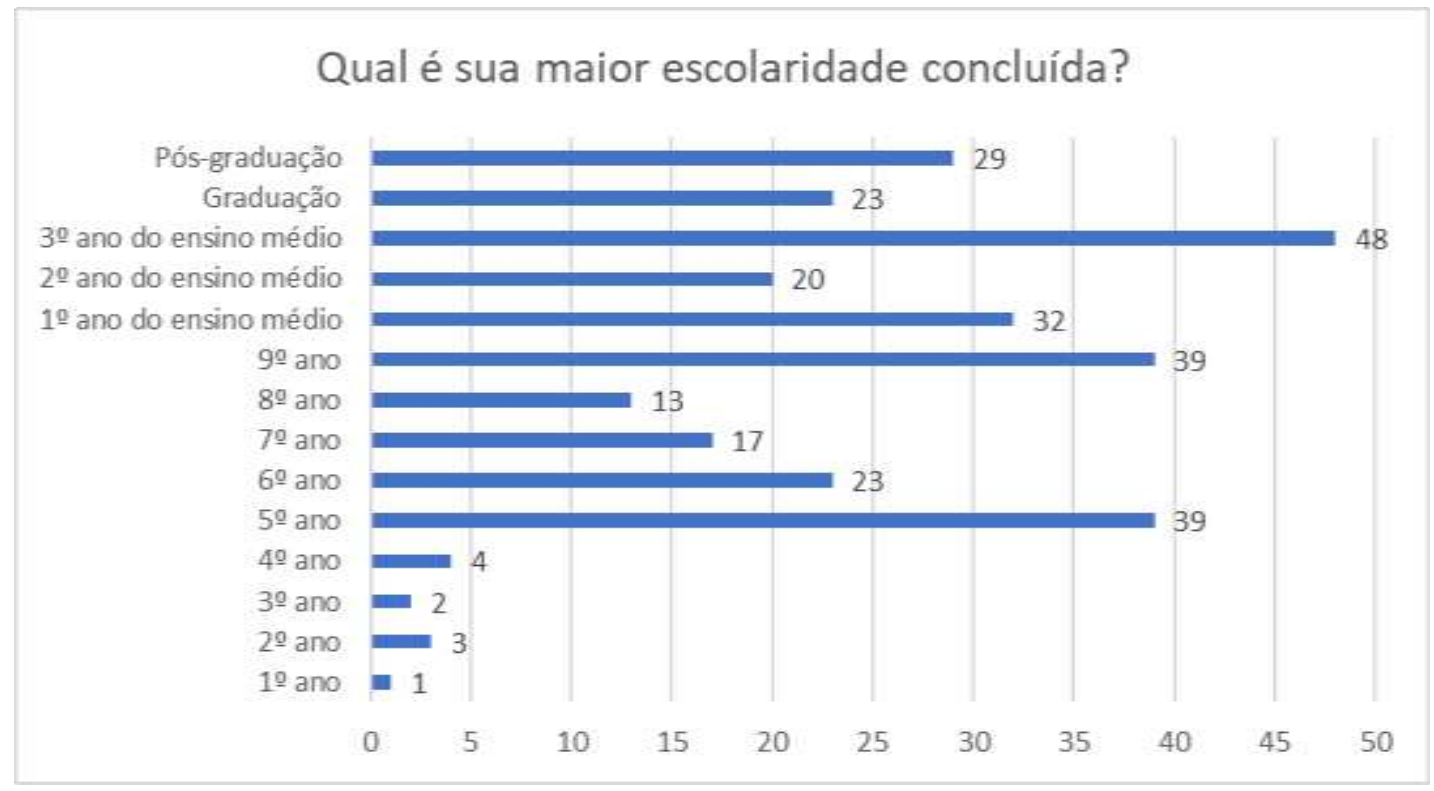

Fonte: Autores.

Quando perguntado sobre se conheciam o termo "microplástico", em geral, 77\% das pessoas responderam "NÃO" (n= $225)$ e apenas $23 \%(n=68)$ já tinham ouvido falar deste termo (Gráfico 3A). Dos que conheciam o termo "microplástico", $84 \%$ eram de Niterói $(n=57)$ e 16\% ( $n=11)$ eram do interior (Gráfico 3B). Em contrapartida, daqueles que desconheciam o termo, 59\% ( $n=132$ ) eram do interior e 41\% ( $n=93$ ) de Niterói (Gráfico 3C). 
Gráfico 3 - A maioria do público entrevistado nunca ouviu falar de microplástico. A) Gráfico das respostas à pergunta "Já ouviu falar do termo “microplástico?”. N=293. B) Gráfico referente à localidade das respostas “sim”. Podemos observar que o público que já ouviu falar em microplástico era de Niterói $(n=57)$ comparado ao interior $(n=11)$. C) Gráfico referente à localidade das respostas "não". Podemos observar que do público que não ouviu falar em microplástico encontramos tanto pessoas de Niterói $(n=93)$ quanto do interior $(n=132)$.

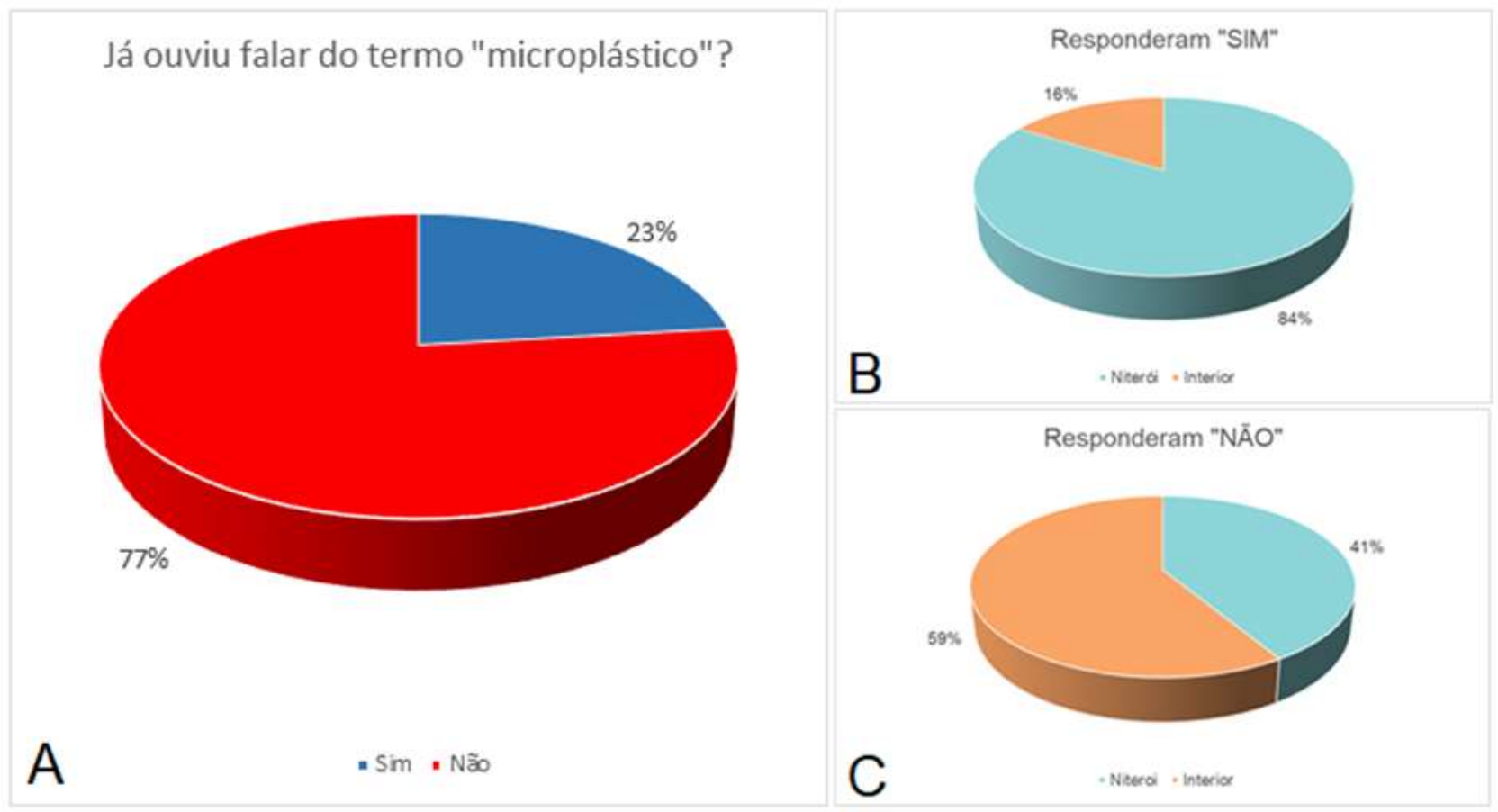

Fonte: Autores.

De acordo com Milfont et al. (2014) existe uma relação linear entre a crença em mudanças climáticas e a distância linha de costa, possivelmente porque os efeitos mais conhecidos das alterações climáticas não são experienciados em primeira mão. Assim, com base neste estudo pode-se sugerir que as pessoas que habitam a zona costeira como Niterói tem maior conhecimento acerca do que são os microplásticos, pois estão em contato direto com os problemas de poluição relacionados.

Além disso, também podemos observar diferenças no nível de escolaridade entre as localidades dos entrevistados que responderam "SIM" e "NÃO". Para aqueles que responderam "SIM", em Niterói, houve uma prevalência de pessoas que estão cursando/cursaram ensino médio (42\%) ou ensino superior (graduação e pós graduação, 50\%). Já no interior houve uma maior frequência de estudantes do ensino médio (55\%) (Gráfico 4). Para aqueles que responderam "NÃO”, em Niterói houve uma maior frequência de estudantes do ensino fundamental I e II, e ensino médio, além de haver uma porcentagem considerável de entrevistados com pós-graduação, enquanto no interior predominaram os estudantes do ensino fundamental II e ensino médio (Gráfico 5) 
Gráfico 4 - Gráficos correspondentes à escolaridade dos entrevistados que responderam "sim" à pergunta "Já ouviu falar do termo “microplástico"?” em Niterói e Interior, respectivamente.

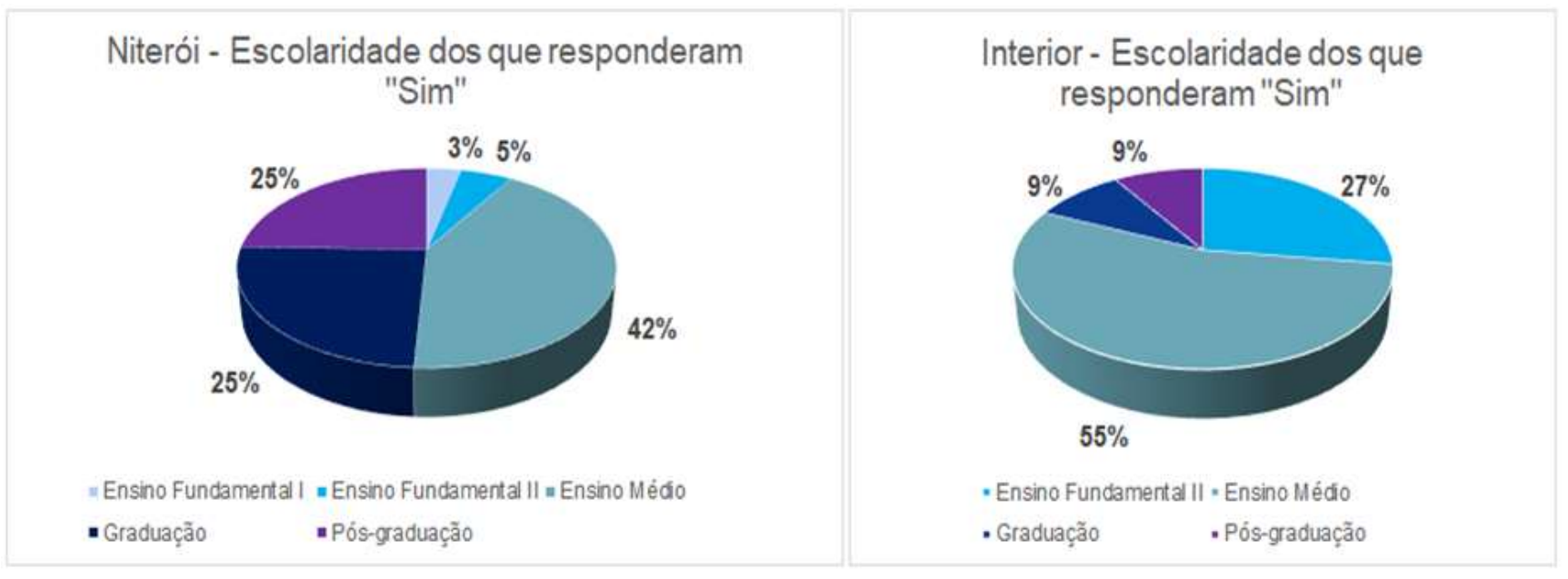

Fonte: Autores.

Gráfico 5 - Gráficos correspondentes à escolaridade dos entrevistados que responderam "não" à pergunta "Já ouviu falar do termo "microplástico"?” em Niterói e Interior, respectivamente.

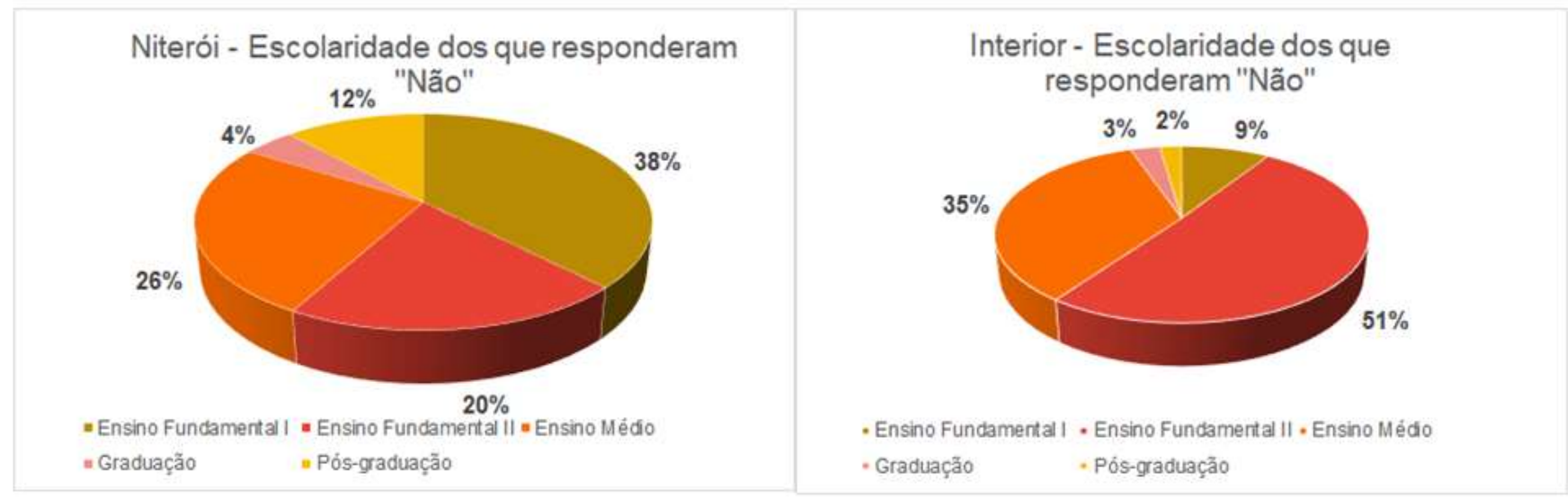

Fonte: Autores.

A partir dos resultados, observa-se que o público que conhecia os microplásticos tinha uma escolaridade mais elevada em Niterói, comparado ao interior, provavelmente sendo um reflexo de seu alto Índice de Desenvolvimento Humano Municipal. Além disso, a presença de uma universidade federal na cidade pode ter favorecido no número de respostas positivas. Outro fato relevante é que, no interior, houve um público composto majoritariamente por estudantes do ensino fundamental e médio, provavelmente devido o trabalho ter ocorrido durante a Semana Nacional de Ciência e Tecnologia. Além disso, vemos que no ensino fundamental esse tema não é discutido como no ensino médio (Castoldi, Bernardi, \& Polinarski, 2009; dos Reis, Martins, \& Rosa, 2017). Portanto, acreditamos que escolaridade possa ser um fator determinante para o conhecimento sobre os microplásticos.

Na segunda seção, perguntamos onde os participantes que responderam "SIM" tinham ouvido falar do termo "microplástico". Com a possibilidade de marcar mais de uma opção, a maioria das pessoas $(61,8 \%)$ tinham conhecimento através da internet. Apesar de ainda não ser o principal meio de comunicação segundo o levantamento mais recente da "Pesquisa Brasileira de Mídia: Hábitos de consumo de mídia pela população brasileira”, a internet cada vez mais se constitui 
como um dos mais influentes instrumentos e fontes de informação. Além disso, 52,9\% $(\mathrm{n}=36)$ dos entrevistados souberam em colégios e faculdades. Logo, os espaços formais de educação continuam sendo fundamentais para a formação cidadã e consciente. Em seguida, 27,9\% $(n=19)$ ouviram falar pela televisão, 23,5\% ( $n=16)$ em conversas com amigos e familiares, $4,4 \%(n=3)$ pelo rádio e apenas 2,9\% $(n=2)$ através de revistas e jornais (Gráfico 6).

Gráfico 6 - Gráfico das respostas à pergunta “Onde você ouviu falar?”. Podemos observar que a maioria respondeu internet ou no ambiente escolar.

\section{Onde você ouviu falar? \\ 68 respostas}

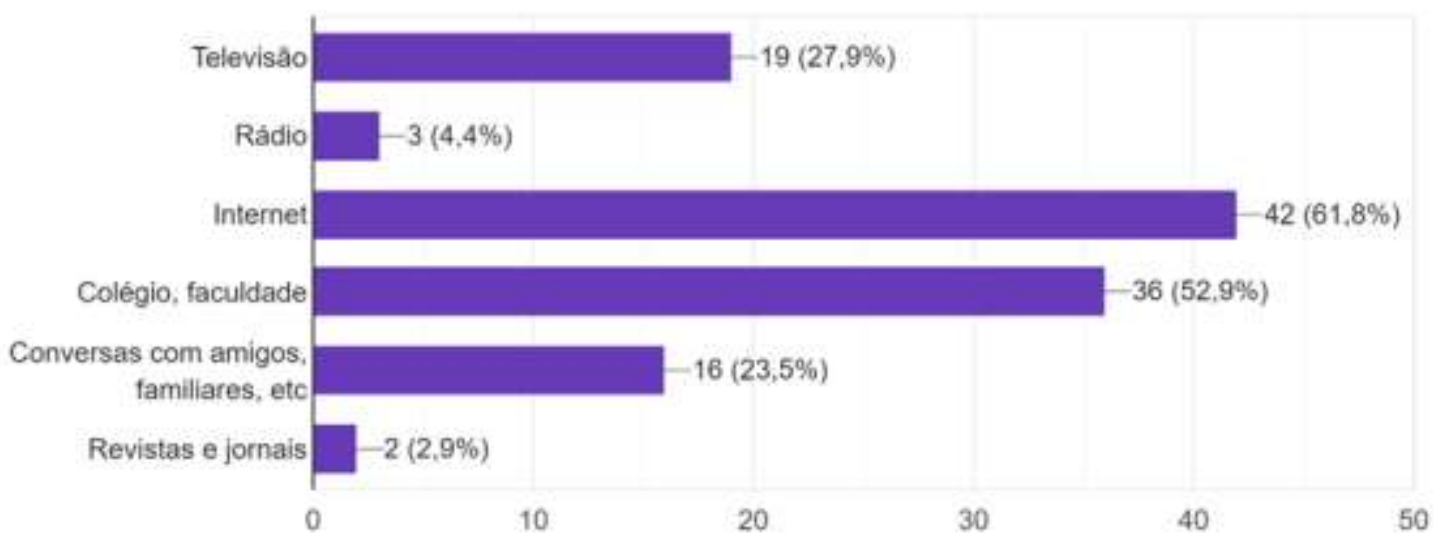

Fonte: Autores.

Em seguida perguntamos quais dos produtos apresentados podem liberar microplásticos, permitindo a marcação de mais de um item. Segundo os participantes, as sacolas de supermercado e as garrafas PET foram os produtos mais escolhidos que podem liberar microplásticos, seguidos de pasta de dente, sabonetes e esfoliantes, pneus, sapatos e, por último, roupas (Gráfico 7). Podemos observar o não conhecimento de que todos os produtos listados são passíveis de liberar microplásticos (Bila, Pereira, \& da Silva, 2019; Hartline et al., 2016). Acreditamos que os mais escolhidos foram os plásticos por serem mais reportados pela mídia como poluidores do meio ambiente (Conceição, Conceição, Dalmas, \& Rosini, 2019). 
Gráfico 7 - Respostas do público sobre quais produtos podem liberar microplásticos. Pelo gráfico das respostas percebemos que o público acredita que principalmente sacolas de supermercado e as garrafas PET podem liberar microplásticos.

\section{Para você, quais destes produtos podem liberar microplásticos? \\ 68 respostas}

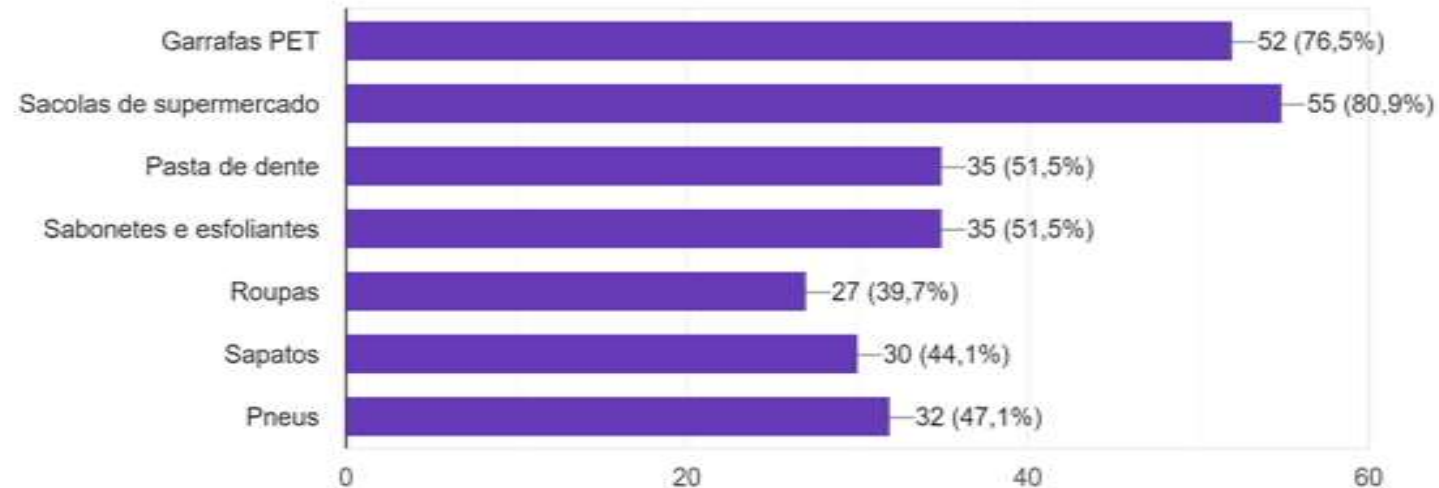

Fonte: Autores.

Quando questionados se achavam que o seu lixo gera microplásticos no ambiente, a maioria dos entrevistados respondeu positivamente com $96 \%(n=65)$ o que nos mostra que eles têm consciência disto (Gráfico 8). Provavelmente, estas respostas são um reflexo da influência dos meios de comunicação sobre os entrevistados, uma vez que o tema "meio ambiente" tem cada vez mais destaque da mídia.

Gráfico 8 - A maioria do público percebe que seu lixo gera microplásticos. Respostas à pergunta "Você acha que o seu lixo gera microplásticos no ambiente?" "Sim" n= 65; "Não" n=2 e "Talvez" n=1.

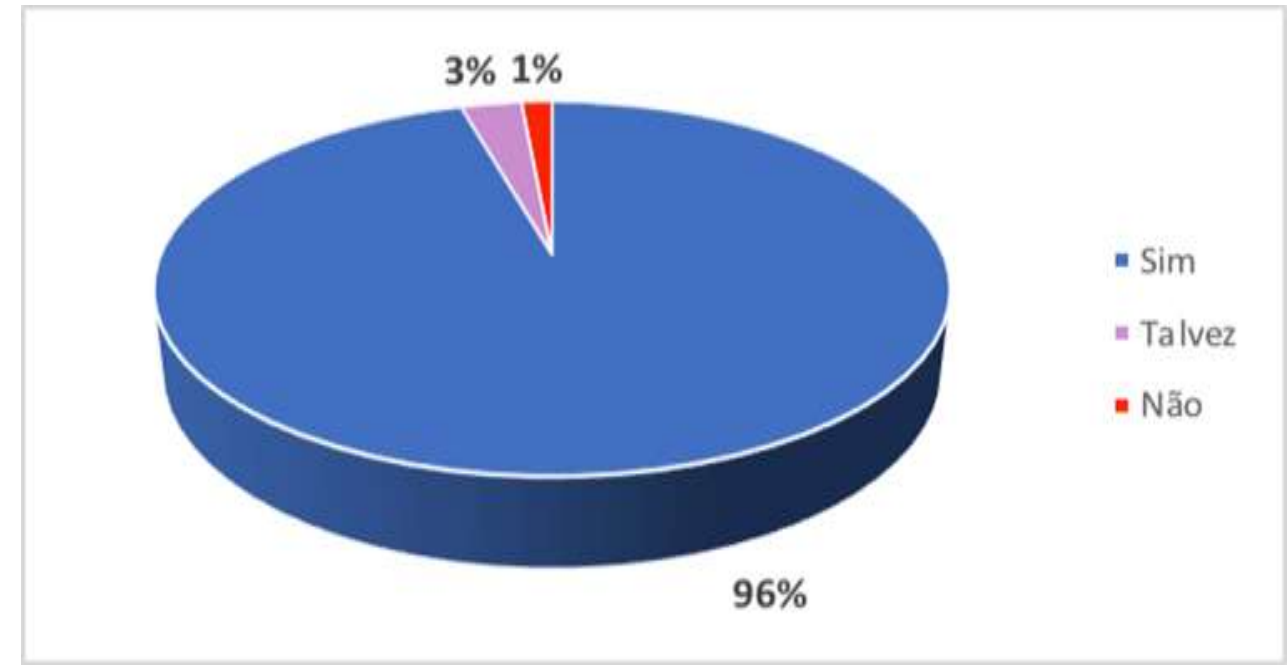

Fonte: Autores.

Deste modo, a partir do resultado acima, esperávamos que a maioria fizesse a coleta seletiva, uma vez que possuem consciência ambiental. Apesar disso, quando questionados se separam o lixo comum do reciclado, a maioria dos entrevistados respondeu que "Não", o que reflete que ainda não é um hábito comum separar o lixo entre orgânico e reciclável, demonstrando a necessidade da educação ambiental e a implementação e/ou incentivo à coleta seletiva nos municípios (Gráfico 9). 
Gráfico 9 - A maioria do público não separa o lixo comum do reciclado. Gráfico das respostas à pergunta "Em sua residência, você e sua família separam o lixo comum do reciclado?". Sim" n= 25; "Não" n= 40 e "Talvez" n= 3 .

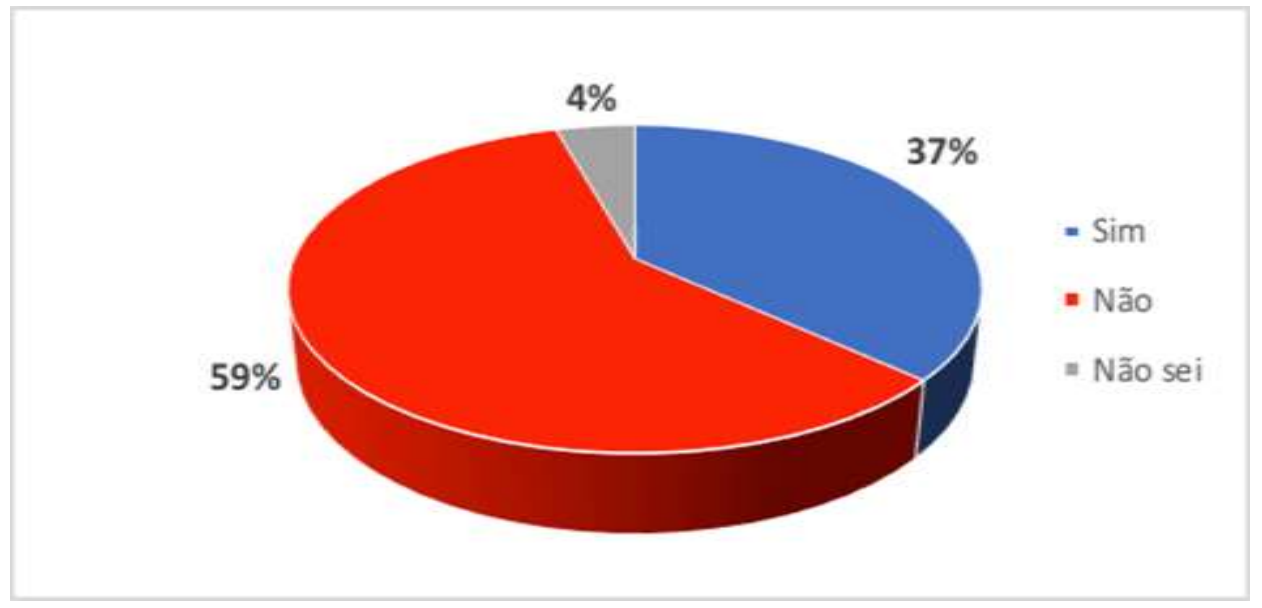

Fonte: Autores.

Perguntados sobre como acham que os plásticos se decompõem na natureza, percebemos que a crença de que os plásticos não se decompõem ainda é predominante segundo os entrevistados, sendo a opção mais escolhida com 34 votos (Gráfico 10). A segunda opção mais votada foi "degradação oxidativa", seguida por "biodegradação por bactérias", “decomposição espontânea”, “decomposição por luz”, “degradação lenta”. Na opção "outros” tivemos duas respostas: “Não sei" e "de tudo um pouco", a qual podemos classificar como a resposta correta.

Gráfico 10 - A maioria dos entrevistados que já ouviu falar em microplásticos acredita que os plásticos não se decompõem na natureza. Gráfico das respostas à pergunta “Como você acha que os plásticos se decompõem na natureza?

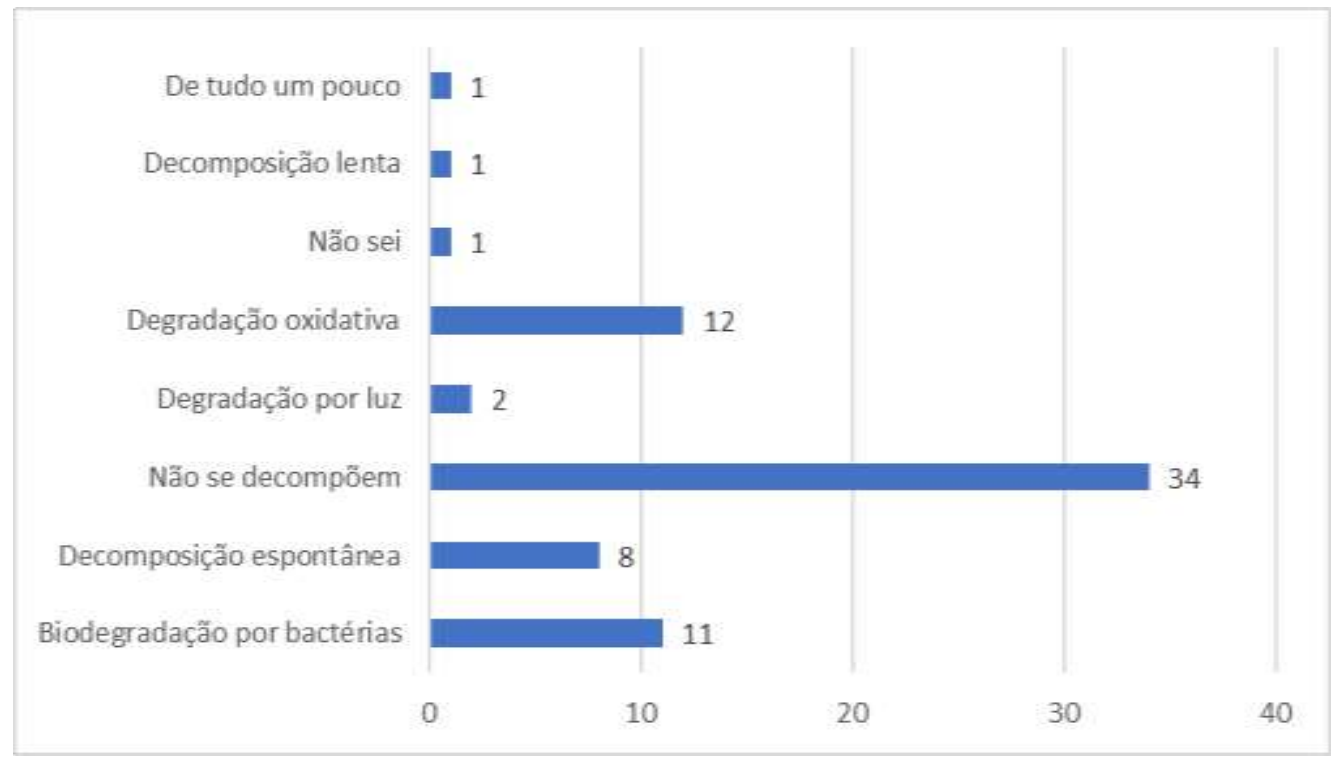

Fonte: Autores.

Atualmente, Dias (2016) apresenta os tipos de degradação dos polímeros em relação a seus agentes: agentes físicos através da radiação solar e outras radiações, temperatura e atrito mecânico e intenso; agentes químicos através de água, ácidos, bases, solventes, outros produtos químicos, oxigênio, o ozônio, e outros poluentes atmosféricos; e agentes biológicos através de micro-organismos, tais como fungos e bactérias. Porém, poucas descobertas foram realizadas com biodegradação por 
bactérias (Yoshida et al., 2016). Assim, estima-se que os plásticos levem cerca de 400 anos para se decompor (Shah, Hasan, Hameed, \& Ahmed, 2008).

Após a análise das respostas à questão se achavam que os microplásticos afetam nossa saúde, a maioria dos entrevistados ( $n=66)$ acreditam que os microplásticos podem afetar a saúde (Gráfico 11). Ainda que seja evidente que os microplásticos se tornaram um dos mais preocupantes contaminantes da sociedade atual, informações conclusivas sobre seus impactos para a saúde humana estão ainda sendo estudadas e debatidas pela comunidade científica (Barboza, Dick Vethaak, Lavorante, Lundebye, \& Guilhermino, 2018; Prata, da Costa, Lopes, Duarte, \& Rocha-Santos, 2020)

Gráfico 11 - A maioria das pessoas entrevistadas acreditam que os microplásticos afetam nossa saúde. Gráfico das respostas à pergunta "Você acha que os microplásticos podem afetar nossa saúde?" n= 66 .

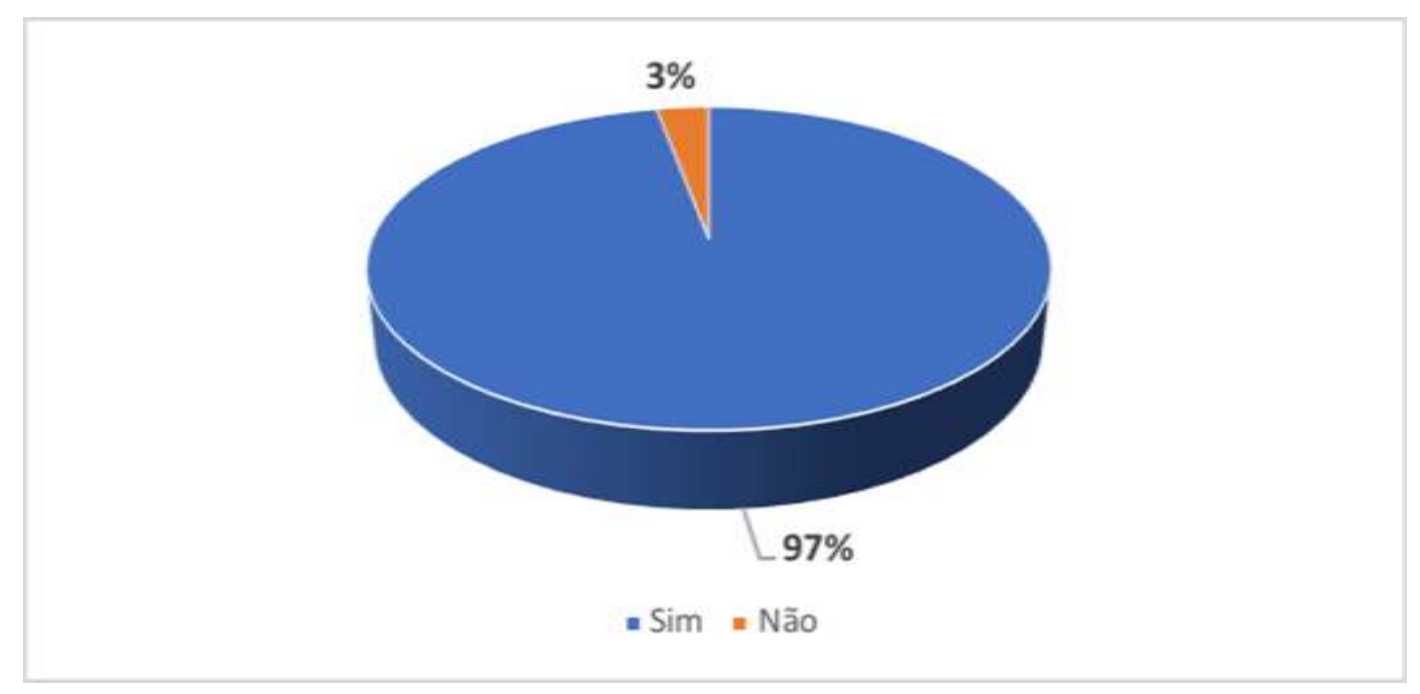

Fonte: Autores.

Por último, quando perguntados sobre quais seres vivos podem sofrer ou serem afetados pela poluição do meio ambiente com microplásticos, a tartaruga marinha continua sendo considerada o animal mais afetado pela poluição de microplásticos segundo os participantes da pesquisa (Gráfico 12). As tartarugas marinhas são consideradas como espécie bandeira, definição que se atribui às espécies que atraem a atenção das pessoas pelo seu carisma e assim são representantes de uma causa ambiental, de forma a conscientizar a opinião pública para a necessidade de conservar o meio ambiente (Luchetta, 2017). 
Gráfico 12 - A tartaruga marinha é o animal mais representativo de sofrer com poluição pelos microplásticos. Gráfico das respostas à pergunta "Quais destes seres vivos podem sofrer ou serem afetados pela poluição do meio ambiente com microplásticos?”. Nesta pergunta, podia-se marcar mais de uma opção.

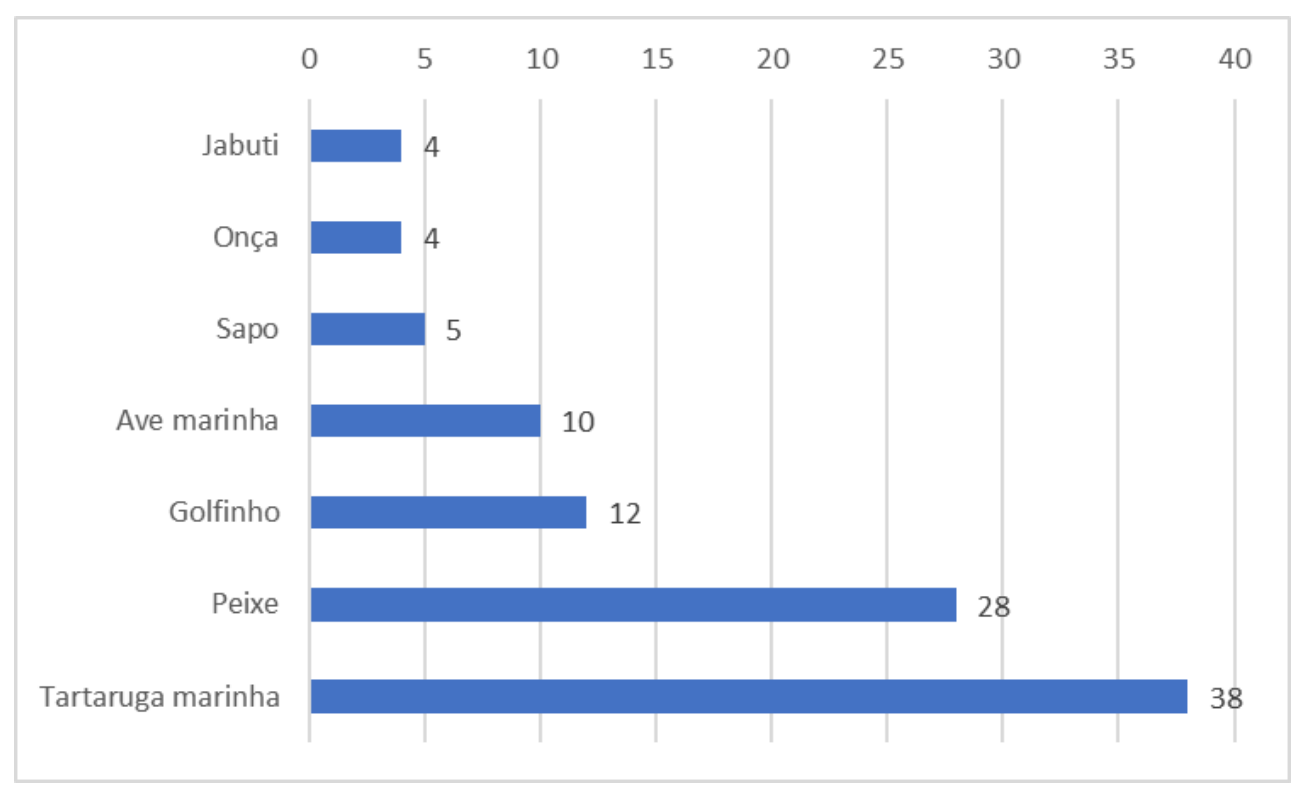

Fonte: Autores.

Além disso, também foram citados os seguintes animais em ordem decrescente de citação: peixe, golfinho, ave marinha, sapo, onça e jabuti. É evidente que a escolha por animais marinhos foi maior, uma vez que os microplásticos estão presentes em sua maior parte nos ambientes aquáticos e, assim, os animais terrestres estão menos suscetíveis à essa poluição.

A atividade "Descobrindo os Microplásticos" foi criada em virtude dos recentes estudos sobre os impactos dos microplásticos no Brasil (Castro et al., 2018; Sul, 2014), e teve como objetivo principal apresentar e divulgar os microplásticos como agentes poluidores do ambiente, em especial no ambiente marinho.

A mediação pode ser feita de diversas formas. Primeiramente, o público era convidado para uma pesca normal, assim como nas brincadeiras de festas juninas (Figura 1A). Porém, ao pegarem o peixe grande de feltro, percebiam que estava contaminado com pequenas pedras representando os microplásticos. Além disso, a presença de peixes menores predados pelos maiores e encontrados no seu trato digestivo indicavam a poluição acumulada, no caso dos microplásticos. Após isso, eram apresentados os verdadeiros contaminantes, os microplásticos, responsáveis pela poluição e contaminação de diversos hábitats do mundo. Além disso, também era mostrado como esses microplásticos vão parar nos oceanos: quando o microplástico é liberado na sua forma primária, como pellet, ou é liberado através da decomposição de plásticos maiores, sendo sua origem secundária (Figura 1B). 
Figura 1 - Atividade "Descobrindo os Microplásticos". A) À direita a Pescaria com peixes de feltro é realizada por um visitante e à esquerda mostra a mesa com utensílios capazes de liberar microplásticos. B) Mediação da atividade, na qual é explicado que microplásticos secundários são formados a partir da degradação de plásticos maiores como, por exemplo, uma meia de nylon.

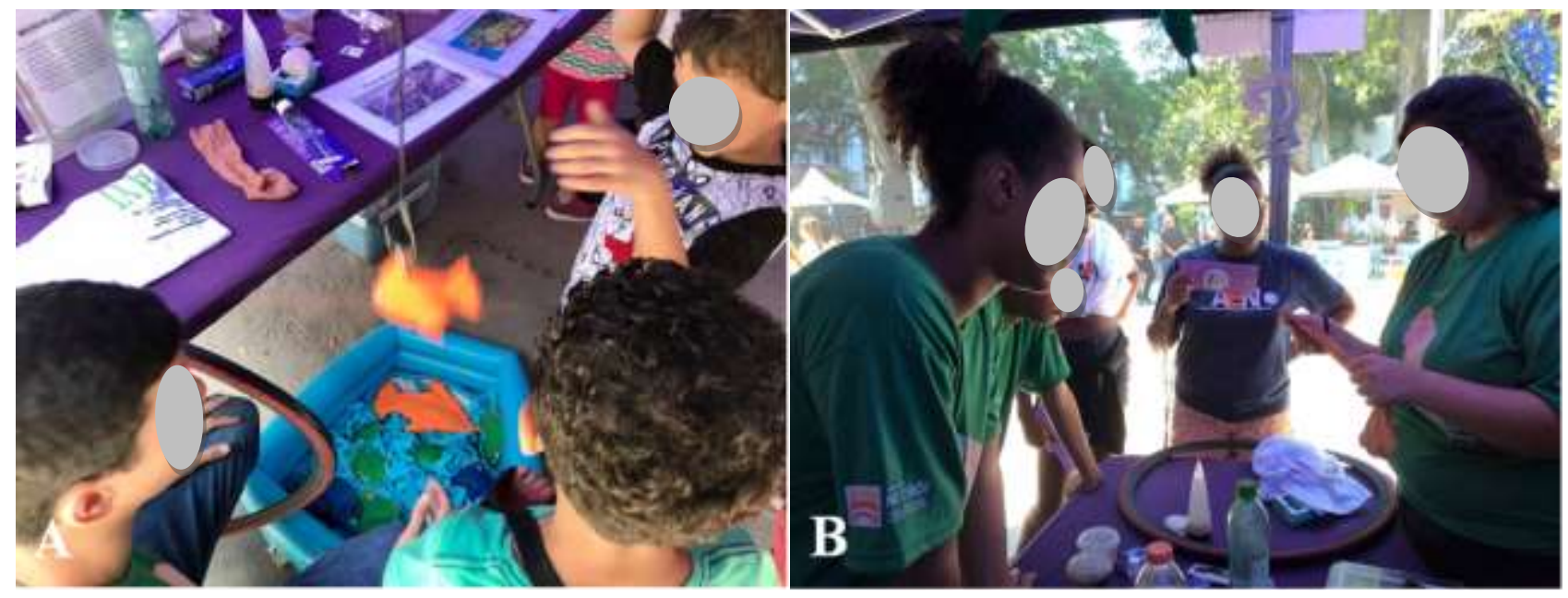

Fonte: Autores.

Inicialmente, os visitantes se mostraram surpresos ao serem apresentados aos microplásticos e, principalmente, ao saberem que estão intimamente associados em seu cotidiano presentes em produtos de uso diário. Os visitantes conseguiram desenvolver um pensamento crítico à medida que eram orientados pelo mediador. Durante a mediação foram abordados desde o uso destes produtos até a poluição marinha e, consequentemente, a bioacumulação e seus impactos ecológicos.

De acordo com Santos (2011), fornecer os conhecimentos relevantes sobre o assunto, de modo que faça relação com o cotidiano dos espectadores, é fundamental para que criem uma ideia crítica embasada cientificamente sobre esse grave problema social. Do ponto de vista educacional, a atividade desenvolvida facilitou a conscientização e a transposição dos principais conceitos físicos e químicos sobre os microplásticos de maneira contextualizada com a realidade dos participantes.

\section{Considerações Finais}

Durante as ações foi observado um precário conhecimento acerca do tema de poluição por microplásticos nas cidades interioranas em comparação com a cidade litorânea. Deste modo, podemos sugerir que haja uma possível relação entre habitar próximo à zona costeira, como por exemplo Niterói, e conhecer os efeitos e impactos dos microplásticos, uma vez que as pessoas são mais conscientizadas do espaço público que habitam. Contudo, o fator mais determinante é a escolaridade, uma vez que a pesquisa apontou uma maior escolaridade entre aqueles que conheciam os microplásticos.

De acordo com a pesquisa de percepção ambiental o microplástico, como agente poluidor, ainda não é um tema conhecido pela maior parte da população. Assim, esse potencial deve ser explorado na divulgação científica, sendo necessário estimular que as pessoas façam reflexões e as instiguem a saber mais para que consigam uma mudança de hábitos, especialmente a respeito do lixo e seu descarte.

Portanto, uma forma de promover a educação ambiental é através da percepção ambiental utilizando espaços não formais de educação. Desta forma, acreditamos que o desenvolvimento da atividade "Descobrindo os microplásticos" pode servir como instrumento de incentivo à sociedade a participar do desenvolvimento sustentável. Deste modo, as pessoas são chamadas a repensar, reprojetar e reestruturar seus valores, e com o envolvimento de todos favorece a proposta de se pensar no 
futuro. Assim não são mais oferecidas soluções prontas, mas sim, instrumentos para que cada um faça a sua parte.

A partir dessas constatações e reflexões, e considerando o cenário de pandemia de Covid-19, acreditamos que trabalhos futuros possam ser desenvolvidos em ambientes virtuais. Dessa forma, criando estratégias de divulgação científica sobre os microplásticos que favorecem ainda mais a interiorização do conhecimento para além das regiões litorâneas.

\section{Agradecimentos}

Agradecemos ao CNPq por meio do Edital para ações da Semana Nacional de Ciência e Tecnologia, à Pró-Reitoria de Extensão da UFF pelas bolsas de extensão que são fundamentais para o CST, ao Professor Bernardo Antônio Perez da Gama que foi um grande entusiasta do projeto e do tema e aos mediadores do CST que são essenciais para todas as atividades do CST.

\section{Referências}

Alves, G. H. V. S., Fragel-Madeira, L., de Azeredo, T. V., Castro, H. C., Pereira, G. R., \& Coutinho-Silva, R. (2020). Low-Cost Scientific Exhibition: A Proposal to Promote Science Education. Creative Education, 11(05), 760-782. 10.4236/ce.2020.115055

Alves, G. H. V. S, Pereira, M. L. O. V. C., Motta, J. M., Lira, L. B. S., Souza, T. V. de A., Silva, A. S., \& Fragel-Madeira, L. (2020). Ciências Sob Tendas: Portfólio de atividades - Natureza (p. 49). p. 49. http://educapes.capes.gov.br/handle/capes/571832

Alves, Marins, M. M., Pereira, G. R., \& Fragel-Madeira, L. (2019). Ciências sob tendas levando a extensão ainda mais longe. In F. J. F. Coelho, P. TamiassoMartinhon, \& C. Sousa (Orgs.), Educação em ciências, saúde e extensão universitária. http://deposita.ibict.br/bitstream/deposita/89/2/Miolo_FranciscoJos\%c3\%a9_Brenner-Final.pdf

Amorim Filho, O. B., Kohler, H. C., \& Barroso, L. C. (2003). Epistemologia, cidade e meio ambiente. Editora PUC Minas.

Andrady, A. L. (2011). Microplastics in the marine environment. Marine pollution bulletin, 62(8), 1596-1605. https://doi.org/10.1016/j.marpolbul.2011.05.030

Andrady, A. L., \& Neal, M. A. (2009). Applications and societal benefits of plastics. Philosophical Transactions of the Royal Society B: Biological Sciences, 364(1526), 1977-1984. 10.1098/rstb.2008.0304

Barboza, L. G. A., Dick Vethaak, A., Lavorante, B. R. B. O., Lundebye, A. K., \& Guilhermino, L. (2018, agosto 1). Marine microplastic debris: An emerging issue for food security, food safety and human health. Marine Pollution Bulletin, Vol. 133, p. 336-348. 10.1016/j.marpolbul.2018.05.047

Bila, D. M., Pereira, T., \& da Silva, A. A. (2019). Quantificação E Caracterização De Microplásticos Em Produtos De Cuidado Pessoal. Congresso Brasileiro de Engenharia Sanitária e Ambiental. http://abes.locaweb.com.br/XP/XPEasyArtigos/Site/Uploads/Evento45/TrabalhosCompletosPDF/II-386.pdf

Brach, L., Deixonne, P., Bernard, M.-F., Durand, E., Desjean, M.-C., Perez, E., ... Ter Halle, A. (2018). Anticyclonic eddies increase accumulation of microplastic in the North Atlantic subtropical gyre. Marine pollution bulletin, 126, 191-196. 10.1016/j.marpolbul.2017.10.077

Brasil. Lei 9795/99 - Política Nacional de Educação Ambiental. , (1999).

Bueno, W. C. (2010). Comunicação cientifica e divulgação científica: aproximações e rupturas conceituais. Informação \& Informação, 15(supl), 1-12. 10.5433/1981-8920.2010v15nesp.p1

Castoldi, R., Bernardi, R., \& Polinarski, C. A. (2009). Percepção dos problemas ambientais por alunos do ensino médio. Revista Brasileira de Ciência, Tecnologia e Sociedade, 1(1)

Castro, R. O., da Silva, M. L., \& de Araújo, F. V. (2018). Review on microplastic studies in Brazilian aquatic ecosystems. Ocean \& Coastal Management, 165, 385-400. https://doi.org/10.1016/j.ocecoaman.2018.09.013

Chaer, G., Diniz, R. R. P., \& Ribeiro, E. A. (2012). A técnica do questionário na pesquisa educacional. Revista Evidência, 7(7).

Conceição, M. M., Conceição, J. T. P., Dalmas, F. B., \& Rosini, A. M. (2019). O plástico como vilão do meio ambiente. Revista Geociências-UNG-Ser, 18(1), 50-53. http://dx.doi.org/10.33947/1981-7428-v18n1-4024

Cunha, A. S. da, \& Leite, E. B. (2009). Percepção ambiental: implicações para a educação ambiental. Sinapse Ambiental, 66-79.

da Costa, J. P., Santos, P. S. M., Duarte, A. C., \& Rocha-Santos, T. (2016). (Nano) plastics in the environment-sources, fates and effects. Science of the Total Environment, 566, 15-26. https://doi.org/10.1016/j.scitotenv.2016.05.041

Machado, A. A S., Kloas, W., Zarfl, C., Hempel, S., \& Rillig, M. C. (2018). Microplastics as an emerging threat to terrestrial ecosystems. Global change biology, 24(4), 1405-1416. https://doi.org/10.1111/gcb.14020

Derraik, J. G. B. (2002). The pollution of the marine environment by plastic debris: a review. Marine pollution bulletin, 44(9), 842-852. https://doi.org/10.1016/S0025-326X(02)00220-5 
Dias, J. de C. (2016). Rotas de destinação dos resíduos plásticos e seus aspectos ambientais: uma análise da potencialidade da biodegradação. Dissertação de Mestrado. Programa de Pós-graduação em Planejamento Energético. Universidade Federal do Rio de Janeiro.

dos Reis, L. N. G., Martins, M. T., \& Rosa, D. A. (2017). Educação Ambiental frente a reforma do Ensino Médio no Brasil. Periódico Eletrônico Fórum Ambiental da Alta Paulista, 13(2). http://dx.doi.org/10.17271/1980082713220171554

Eriksen, M., Lebreton, L. C. M., Carson, H. S., Thiel, M., Moore, C. J., Borerro, J. C., \& Reisser, J. (2014). Plastic Pollution in the World's Oceans: More than 5 Trillion Plastic Pieces Weighing over 250,000 Tons Afloat at Sea. PLoS ONE, 9(12). 10.1371/journal.pone.0111913

Galgani, F., Pham, C. K., \& Reisser, J. (2017). Plastic pollution. Frontiers in Marine Science, 4, 307. https://doi.org/10.3389/fmars.2017.00307

Geyer, R., Jambeck, J. R., \& Law, K. L. (2017). Production, use, and fate of all plastics ever made. Science advances, 3(7), e1700782. $10.1126 /$ sciadv. 1700782

Hall, N. M., Berry, K. L. E., Rintoul, L., \& Hoogenboom, M. O. (2015). Microplastic ingestion by scleractinian corals. Marine Biology, 162(3), 725-732. https://doi.org/10.1007/s00227-015-2619-7

Hartline, N. L., Bruce, N. J., Karba, S. N., Ruff, E. O., Sonar, S. U., \& Holden, P. A. (2016). Microfiber masses recovered from conventional machine washing of new or aged garments. Environmental science \& technology, 50(21), 11532-11538. https://doi.org/10.1021/acs.est.6b03045

Hengstmann, E., Tamminga, M., Vom Bruch, C., \& Fischer, E. K. (2018). Microplastic in beach sediments of the Isle of Rügen (Baltic Sea)-Implementing a novel glass elutriation column. Marine pollution bulletin, 126, 263-274. https://doi.org/10.1016/j.marpolbul.2017.11.010

Islam, M. S., \& Tanaka, M. (2004). Impacts of pollution on coastal and marine ecosystems including coastal and marine fisheries and approach for management: a review and synthesis. Marine pollution bulletin, 48(7-8), 624-649. https://doi.org/10.1016/j.marpolbul.2003.12.004

Jacobucci, D. F. C. (2008). Contribuições dos espaços não-formais de educação para a formação da cultura científica. Em extensão, 7(1). http://www.seer.ufu.br/index.php/revextensao/article/view/20390/10860

Jambeck, J. R., Geyer, R., Wilcox, C., Siegler, T. R., Perryman, M., Andrady, A., Narayan, R., \& Law, K. L. (2015). Plastic waste inputs from land into the ocean. Science, 347(6223), 768-771. 10.1126/science.1260352

Kaza, S., Yao, L., Bhada-Tata, P., \& Van Woerden, F. (2018). What a waste 2.0: a global snapshot of solid waste management to 2050. World Bank Publications.

Kershaw, P. J. (2016). Marine plastic debris and microplastics-Global lessons and research to inspire action and guide policy change.

Li, R., Zhang, L., Xue, B., \& Wang, Y. (2019). Abundance and characteristics of microplastics in the mangrove sediment of the semi-enclosed Maowei Sea of the south China sea: New implications for location, rhizosphere, and sediment compositions. Environmental Pollution, 244, 685-692.

Luchetta, A. C. de C. B. (2017). Tartarugas marinhas do Parque Estadual Marinho da Laje de Santos e seu potencial como espécie bandeira na sensibilização de usuários. http://hdl.handle.net/11449/151834

Mato, Y., Isobe, T., Takada, H., Kanehiro, H., Ohtake, C., \& Kaminuma, T. (2001). Plastic resin pellets as a transport medium for toxic chemicals in the marine environment. Environmental science \& technology, 35(2), 318-324. https://doi.org/10.1021/es0010498

Melazo, G. C. (2005). Percepção ambiental e educação ambiental: uma reflexão sobre as relações interpessoais e ambientais no espaço urbano. Olhares \& Trilhas, 6(1). http://www.seer.ufu.br/index.php/olharesetrilhas/article/view/3477

Milfont, T. L., Evans, L., Sibley, C. G., Ries, J., \& Cunningham, A. (2014). Proximity to coast is linked to climate change belief. PLoS One, 9(7), e103180. https://doi.org/10.1371/journal.pone.0103180

Moore, C. J. (2008). Synthetic polymers in the marine environment: a rapidly increasing, long-term threat. Environmental research, 108(2), 131-139. https://doi.org/10.1016/j.envres.2008.07.025

Olivatto, G P, Carreira, R., Tornisielo, V. L., \& Montagner, C. C. (2018). Microplásticos: Contaminantes de preocupação global no Antropoceno. Revista Virtual de Química, 10(6), 1968-1989. http://dx.doi.org/10.21577/1984-6835.20180125

Olivatto, Glaucia P, Martins, M. C. T., Montagner, C. C., Henry, T. B., \& Carreira, R. S. (2019). Microplastic contamination in surface waters in Guanabara Bay, Rio de Janeiro, Brazil. Marine pollution bulletin, 139, 157-162. https://doi.org/10.1016/j.marpolbul.2018.12.042

Pacheco, É., \& Silva, H. P. (2007). Compromissos epistemológicos do conceito de percepção ambiental. Rio de Janeiro: Departamento de Antropologia, Museu Nacional e Programa EICOS/UFRJ.

Palma, I. R. (2005). Análise da percepção ambiental como instrumento ao planejamento da educação ambiental. http://hd1.handle.net/10183/7708

PlasticsEurope. (2018). Annual review 2017-2018. PlasticsEurope AISBL Brussels.

Prata, J. C., da Costa, J. P., Lopes, I., Duarte, A. C., \& Rocha-Santos, T. (2020). Environmental exposure to microplastics: An overview on possible human health effects. Science of the Total Environment, 702, 134455. https://doi.org/10.1016/j.scitotenv.2019.134455

Rochman, C. M. (2016). The role of plastic debris as another source of hazardous chemicals in lower-trophic level organisms. In Hazardous chemicals associated with plastics in the marine environment (p. 281-295). Springer. https://doi.org/10.1007/698_2016_17

Santos, E. M. dos. (2011). Educação Ambiental no Ensino de Química: propostas curriculares brasileiras. https://orcid.org/0000-0002-6109-6830 
Research, Society and Development, v. 10, n. 7, e45210715411, 2021

(CC BY 4.0) | ISSN 2525-3409 | DOI: http://dx.doi.org/10.33448/rsd-v10i7.15411

Shah, A. A., Hasan, F., Hameed, A., \& Ahmed, S. (2008). Biological degradation of plastics: a comprehensive review. Biotechnology advances, 26(3), 246265. https://doi.org/10.1016/j.biotechadv.2007.12.005

Sharma, S., \& Chatterjee, S. (2017). Microplastic pollution, a threat to marine ecosystem and human health: a short review. Environmental Science and Pollution Research, 24(27), 21530-21547. 10.1007/s11356-017-9910-8

Soares, A., Dorlivete, P., Shitsuka, M., Parreira, F. J., \& Shitsuka, R. (2018). Metodologia Da Pesquisa Científica. Recuperado de Brasil website: http://repositorio.ufsm.br/handle/1/15824

Sul, J. A. I. do. (2014). Contaminação ambiental por microplásticos em Fernando de Noronha, Abrolhos e Trindade. https://repositorio.ufpe.br/handle/123456789/18853

Sundt, P., Schulze, P.-E., \& Syversen, F. (2014). Sources of microplastic-pollution to the marine environment. Mepex for the Norwegian Environment Agency, 86

Van Cauwenberghe, L., Devriese, L., Galgani, F., Robbens, J., \& Janssen, C. R. (2015). Microplastics in sediments: a review of techniques, occurrence and effects. Marine environmental research, 111, 5-17. https://doi.org/10.1016/j.marenvres.2015.06.007

Waller, C. L., Griffiths, H. J., Waluda, C. M., Thorpe, S. E., Loaiza, I., Moreno, B., \& Hughes, K. A. (2017). Microplastics in the Antarctic marine system: an emerging area of research. Science of the total environment, 598, 220-227. https://doi.org/10.1016/j.scitotenv.2017.03.283

Wilcox, C., Van Sebille, E., \& Hardesty, B. D. (2015). Threat of plastic pollution to seabirds is global, pervasive, and increasing. Proceedings of the National Academy of Sciences, 112(38), 11899-11904. https://doi.org/10.1073/pnas.1502108112

Worm, B., Lotze, H. K., Jubinville, I., Wilcox, C., \& Jambeck, J. (2017). Plastic as a persistent marine pollutant. Annual Review of Environment and Resources, 42. https://doi.org/10.1146/annurev-environ-102016-060700

Wright, S. L., Thompson, R. C., \& Galloway, T. S. (2013). The physical impacts of microplastics on marine organisms: a review. Environmental pollution, 178, 483-492. https://doi.org/10.1016/j.envpol.2013.02.031

Yoshida, S., Hiraga, K., Takehana, T., Taniguchi, I., Yamaji, H., Maeda, Y., \& Oda, K. (2016). A bacterium that degrades and assimilates poly (ethylene terephthalate). Science, 351(6278), 1196-1199. 10.1126/science.aad6359 